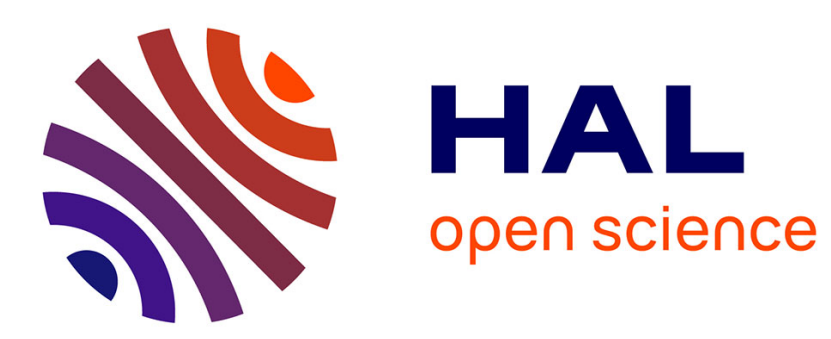

\title{
POLYPHASE SUBSTRATE ELLIPSOMETRY - A KINETIC INVESTIGATION
}

\author{
E. Roberts-Sengier, M. Hamilton, R. Hunt
}

\section{To cite this version:}

E. Roberts-Sengier, M. Hamilton, R. Hunt. POLYPHASE SUBSTRATE ELLIPSOMETRY - A KINETIC INVESTIGATION. Journal de Physique Colloques, 1983, 44 (C10), pp.C10-199-C10-203. 10.1051/jphyscol:19831041 . jpa-00223498

\section{HAL Id: jpa-00223498 https://hal.science/jpa-00223498}

Submitted on 1 Jan 1983

HAL is a multi-disciplinary open access archive for the deposit and dissemination of scientific research documents, whether they are published or not. The documents may come from teaching and research institutions in France or abroad, or from public or private research centers.
L'archive ouverte pluridisciplinaire HAL, est destinée au dépôt et à la diffusion de documents scientifiques de niveau recherche, publiés ou non, émanant des établissements d'enseignement et de recherche français ou étrangers, des laboratoires publics ou privés. 


\title{
POLYPHASE SUBSTRATE ELLIPSOMETRY - A KINETIC INVESTIGATION
}

\author{
E.F.I. Roberts-Sengier, M.A. Hamilton and R. Hunt \\ Department of Metaliurgy and Materials Engineering, City of London \\ Polytechnic, Whitechapel High Street, London EI 7PF, U.K.
}

\begin{abstract}
Résumé - L'utilité de I'ellipsométrie est augmentée si on peut travailler sur des substrats inhomogènes. On présente un modèle et on 1 'expérimente par une étude cinétique du système $\mathrm{Ti} / \mathrm{TiH}_{2}$.

Abstract - The usefulness of ellipsometry is enhanced if it is able to work on inhomogeneous substrates. A model is presented and tested by an investigation of the kinetics of the $\mathrm{Ti} / \mathrm{TiH}_{2}$ system.
\end{abstract}

1. Introduction. Optical techniques have been central to the qualitative and quantitative characterisation of solids. Interest in the solid state focused attention upon techniques capable of analysing the reflected beam spectroreflectometry and spectroellipsometry. The examination of mixed or inhomogeneous substrates has been accepted as a concommitant aspect of using spectroreflectometry but has received little attention in ellipsometry.

Despite their apparent simplicity optical studies of solids have been beset by experimental and analytical problems. Non-ideality has been critical, nevertheless there has been reasonably good agreement among the optical constants for solids if some concessions are made to purity, modes of preparation and methods of measurement. These results have, in the main, been conducted upon fairly pure polycrystalline or single crystal elements or solid solutions. Occasionally mention is made of substrate quality, thus Hayfield (1) working on titanium said "For polycrysta1line materials...there is some possibility that provided both films and substrate are fine grained and randomly orientated, the effects of anisotropy are likely to be cancelled out". This would appear to be the pragmatic solution adopted by most ellipsometrists working on the diagnosis of filmed systems. Inhomogeneity has mainly been considered as a function of substrate/film depth and has been dealt with since Drude (2), Vasicek (3), Abelès (4), Theeten and Aspnes (5).

In the course of applying spectroellipsometry to the optical characterization of jewellery alloys (6) that were, in some cases, composed of two discrete phases two phenomena were observed a) the nulling ellipsometer always found a stable nul1, b) the colour characteristics of the two-phase alloys were displaced from their predicted loci in the CIE colour space. That sensible optical spectra were being produced was not in doubt and importantly, in the case of immiscible phases, the spectra demonstrated classical mixture behaviours (7). (ie. edges remained fixed but their height varied with volume fraction). Several models for mixed phase optical behaviour were tested (8).

Following Maxwe11-Garnett and assuming the Clausius-Mossotti relation to hold in a completely metaliic environment we attempted to analyse the phase mixture through the relation.

$$
\frac{\hat{\varepsilon}_{\text {eff }}-\varepsilon_{\text {matrix }}}{\hat{\varepsilon}_{\text {eff }}+2 \varepsilon_{\text {matrix }}}=q \cdot \frac{\hat{\varepsilon}_{\text {metal }}-\varepsilon_{\text {matrix }}}{\hat{\varepsilon}_{\text {metal }}+2 \varepsilon_{\text {matrix }}}
$$


where $\mathrm{q}$ is the volume fraction of the second phase. This was assumed to hold when $\varepsilon_{\text {matrix }}$ was complex, and was solved for $\varepsilon_{\text {eff }}$. The $M-G$ assumptions in this

instance, ie. small metallic particles in a dielectric environment, were unlikely, however, to hold.

The second model assumed that interference took place between coherent beams from adjacent phases ( $\alpha$ and $\beta$ ) - a weighted average of the amplitude reflection coefficients $\left(\hat{r}_{p}\right.$ and $\hat{r}_{s}$ ) is then measured when light is focused at the detector to a small spot.

$$
\begin{aligned}
& \hat{r}_{p}=(1-q) \hat{r}_{p}^{\alpha}+q \hat{r}_{p}^{\beta} \\
& \hat{r}_{s}=(1-q) \hat{r}_{s}^{\alpha}+q \hat{r}_{s}^{\beta}
\end{aligned}
$$

Thirdly the effective dielectric constant $\hat{\varepsilon}_{\text {ef }} f$ was formed by a linear addition of weighted dielectric constants of the two phases ( $\hat{\varepsilon}^{\alpha}$ al $\hat{\varepsilon}^{\beta}$ respectively).

$$
\hat{\varepsilon}_{\text {eff }}=(1-q) \hat{\varepsilon}^{\alpha}+q \hat{\varepsilon}^{\beta}
$$

When differences between $\hat{\varepsilon}^{\alpha}$ and $\hat{\varepsilon}^{\beta}$ are small this does not give vastly different results from the $M-G$ or interference models. However none of these models gave reflectance curves within $5 \%$ of the experimentally derived reflectances for the copper-silver alloy system.

Finally a matrix formulation (9) was devised and successfully applied to this system and it is with the application of this model to a kinetic experiment, in which the second phase appears during the course of the experiment, that this paper deals.

2. The polyphase ellipsometric model. The derivation of this model has been published and so only the outline and necessary results will be presented here. A duplex phase mixture of phases $\alpha$ and $\beta$ are represented by volume fractions $Q_{\alpha}$ and $Q_{\beta},\left(Q_{\alpha}+Q_{\beta}=1\right)$. The surface is flat and specularly reflecting and the area fractions are considered to equal the volume fractions. When light of known ellipticity is incident upon the phase mixture two wavefronts of differing ellipticity are reflected, these two wavefronts combine to form an average of the two polarization states. The incident light is assumed to be incoherent and the reflected beam can be described by a Stokes vector $\left(S_{R}\right)$ equal to the weighted sum of the normalized Stokes vectors of the reflections from each phase (ie. $S_{\alpha}$ and $S_{\beta}$ )(15)

$$
\mathrm{S}_{\mathrm{R}}=\mathrm{Q}_{\alpha} \mathrm{S}_{\alpha}+\mathrm{Q}_{\beta} \mathrm{S}_{\beta}
$$

It can be shown that :

$$
\text { and } \quad \begin{aligned}
\tan ^{2} \psi_{S} & =Q_{\alpha} \tan ^{2} \psi_{\alpha}+Q \tan ^{2} \psi_{B} \\
\tan \Delta_{S} & =\frac{Q_{\alpha} \tan \psi_{\alpha} \cdot \sin \Delta_{\alpha}+Q_{B} \tan \psi_{\beta} \cdot \sin \Delta_{\beta}}{Q_{\alpha} \tan \psi_{\alpha} \cdot \cos \Delta_{\alpha}+Q_{B} \tan \psi_{B} \cdot \cos \Delta_{B}}
\end{aligned}
$$

3. The formation of titanium hydride by cathodic electrolysis. Electrolytic titanium hydride with a composition somewhat less than the stoichiometric $\mathrm{TiH}_{2}$ may be formed on and within a titanium cathode in aqueous sulphuric acid(0.05M)(10). Suitably mounted annealed titanium" plaquettes $(2 \mathrm{x} 1 \mathrm{~cm})$ were metallographically polished, cleaned and measurea by automatic null-method spectroellipsometry in air. The sample was then cathodically charged at constant temperature, $\mathrm{pH}$ and ambient

*Titanium(Goodfellow Metals Ltd Cambridge) average purity 99.6\%. Impurities (ppm):

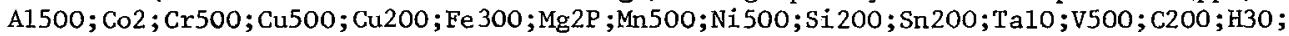
N80;0200. 
density to give a mean thickness of titanium hydride some $29 \mu \mathrm{m}$ thick (11). Subsidiary experiments confirmed the extent, composition, morphology and crystal structure of the hydride (12). The hydride surface was then repolished and the spectral characteristics of the 'bulk' hydride determined. These measurements were also in air but long term observation of the hydride surface confirmed that it did change with time suggesting that the hydride is unreactive (or highly reactive and stable). Furthermore repeated preparations and measurements of the hydride showed a remarkable reproducibility. This behaviour was reminiscent of measurements on ceramics, glasses and certain minerals, and encouraged us to use the in air hydride values. The reproducibility of the titanium $(\Delta, \psi)$ pairs was poor but a corrected evaluation of the titanium substrate $\left(\Delta_{0}, \psi_{0}\right)_{\mathrm{Ti}}$, was computed. This computation assumed the validity of results obtained for titanium in ultra high vacuum ( $\mathrm{n}=1.975 \mathrm{k}=2.733)(13)$ and at several wavelengths. The thickness of a rutile film $(\mathrm{n}=2.421 \mathrm{k}=0.013$ at $400 \mathrm{~nm})$ conforming to $(\Delta, \psi)$ experimental was computed using numerical fitting. This film confirmed an air-formed thickness of $3.4 \mathrm{~nm}$ on the polished titanium. Using this thickness of the film a corrected spectral set of the optical constants of titanium was computed, thus complementing the set derived for the hydride(Figure 1). A wavelength (400 nm) for in situ

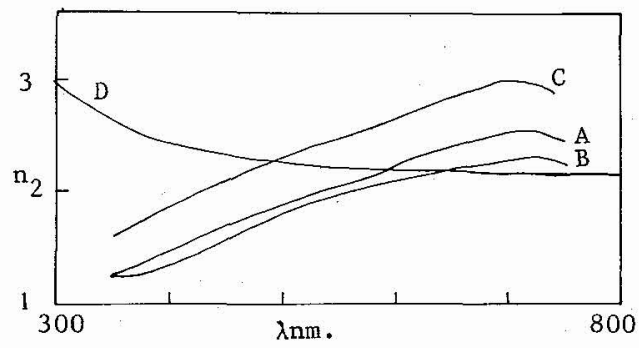

i)

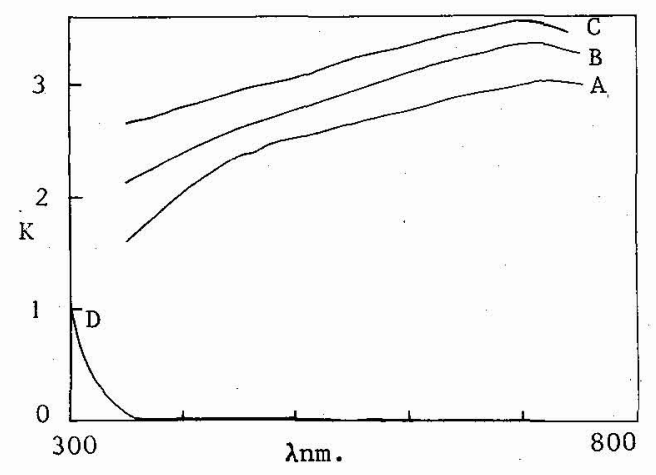

ii)

Fig.1 - Optical constants of A Titanium (experimental), B Titanium (calculated), C Titanium hydride (experimental), D Titanium dioxide (rutile); i) n - values, ii) $k$ - values.

studies of the hydride formation was chosen that optimised the usable differences between the hydride and the titanium $\left(\mathrm{R}_{\mathrm{N}}(\mathrm{Ti}) \simeq 49 \%\right.$ and $\mathrm{R}_{\mathrm{N}}\left(\mathrm{TiH}_{2}\right) \simeq 43 \%$ at $\left.400 \mathrm{~nm}\right)$.

It was, of course, imperative to consider the possibility that the hydride did grow as a film at least at the surface. Electron thin foil experiments had shown that the hydride forms discontinuously although grain-boundaries and free surfaces were enhanced nucleation sites (Figure 2).

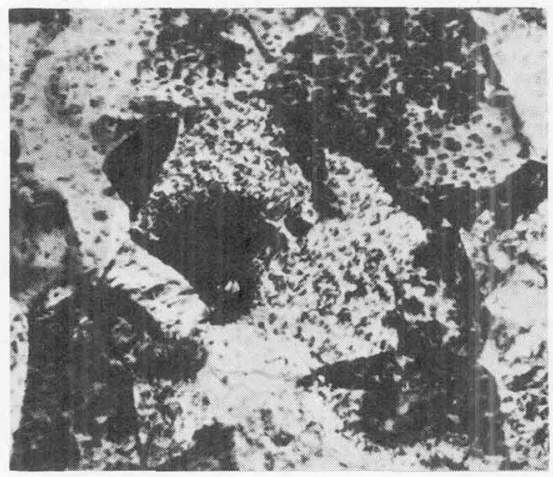

Fig.2 - Electron microscopy thin foils of hydrided titanium ( $x$ 10,000 in origina1). 
The film models established $(\Delta, \psi)$ locii (Figure 3B) that were clearly inconsistent with the experimental results (Figure $3 \mathrm{~A}$ ).

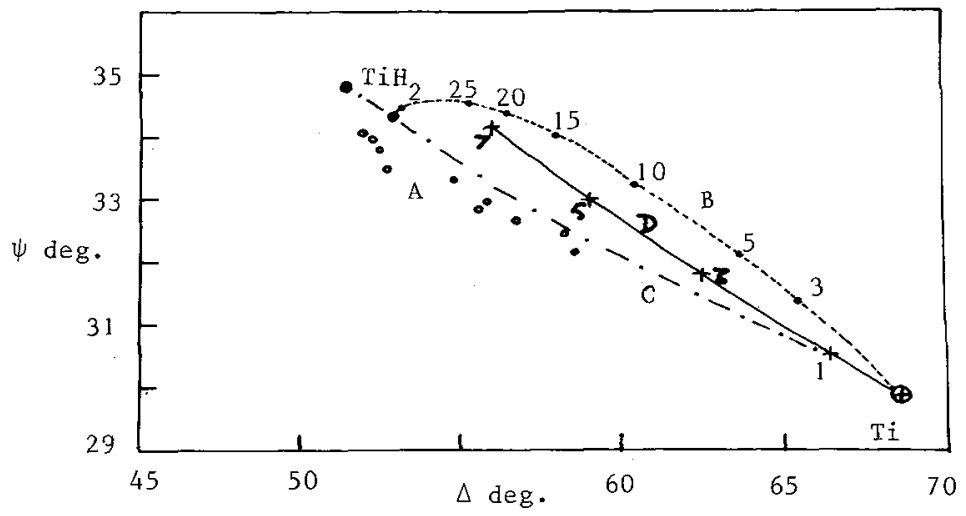

Fig.3 - $\Delta, \psi$ loci of various titanium/titanium hydride models and experimental results. A Experimental points (o); B Titanium substrate + titanium hydride film (numbers $=\mathrm{nm}$ ); $\mathrm{C}$ Mixed titanium/titanium hydride substrate; D Titanium + rutile. overlayer $\left(\mathrm{no}_{\bullet}=\mathrm{nm}\right)$. In situ $\mathrm{n}_{\text {environ }}=1.333, \lambda=400 \mathrm{~nm},=75^{\circ}$.

A much better fit of the experimental data with theoretical curves appeared when the polyphase substrate mode1s were employed (Figure 3C). In this case it was also possible to examine the effects of a rutile film superimposed on the mixed substrate (Figure 3D). This is interesting since a number of workers have proposed that protons traverse any oxide film and combine, as hydrogen at the inner surface (14). The results presented here suggest that the original $3.4 \mathrm{~nm} \mathrm{film}$ of rutile has thinned if not completely dissolved in the electrolyte. Indeed long term immersion of an anodised titanium sample without an impressed current revealed that titanium ions did enter solution and (from interference colours) the film changed thickness.

We suggest therefore that oxide solution does occur and that hydrogen enters the substrate either directly or as protons. There it dissolves in the titanium but where the solubility is exceeded it forms non-stoichiometric hydride TiH.,$x=1.48$ ).

Using the relative quantities (volume fractions) of hydride formed at increasing times it was then possible to suggest a growth curve for the hydride the growth conformed to a logarithmic function $\bar{Q}=.34+.12 \ln \bar{t}$ the correlation for this equation being $\mathrm{r}^{2}=0.981$. Solubility measurements (1I) have indicated that solution follows a linear function and that hydride thickening follows a parabolic function (ibid). These measurements were not sensitive to the quantity of hydride formed in the first stages (ie. before surface coverage was complete) and it is consistent with a diffusion controlled reaction through an intervening barrier. There was, however, an indication that the mean composition of the hydride was lower in the initial period and this may very well have been due to an overestimate of the quantity of hydride formed or the failure to take into account the heterogeneous two-phase nature of the system.

4. Conclusion. There are frequent occasions when ellipsometric observations are made on polyphase, inhomogeneous substrates, likewise there may be reactions which modify a substrate (sic induce phase changes). These modifications or the inhomogeneity may be usefuliy studied as functions of other independent variables. In this particular case a model for polyphase substrate, eliipsometric characteristics have been employed in a dynamic study of in situ hydrogenation of titanium and confirm. that titanium hydride develops not as a film but as a precipitate which grows with time to give complete surface conversion. The hydride appears to grow either after complete or partial dissolution of the air-formed film in dilute 
sulphuric acid. The bulk hydride appears to be stable and unreactive and to possess its own distinct spectra. It is metallic and can be polished to provide a fine specular surface.

The optical model has thus provided evidence of its application in a) using known spectra to quantify the proportion of phases present and b) that it can be inverted to provide an unknown spectra if the proportions of several alloys (with identical phases) are previously known.

\section{Bibliography}

1. Hayfield, P C S., White, GW T., "EIlipsometry in the measurement of surfaces and thin films". NBS Misc.Publn.256 (1963) pp 179.

2. Drude, P. Wied.Ann.der Physik 1899, 36, 532, 865.

3. Vasicek, A., "Optics of thin films". North Holland (1960).

4. Abelès, F., "E1lipsometry in the measurement of surfaces and thin films". NBS Misc.Publn.256 (1963) pp 41.

5. Theeten, J B., Aspres, D E. Ann.Rev.Mater.Sci.,1981, 11, 97-122.

6. Roberts, E F I.,Clarke, K M. Gold Bull., 1979, 12, 9-19.

7. Roberts, E F I.,Clarke, K M., Hunt, R., Gold Bull., 1980, 42, 71-80.

8. Clarke, K M. PhD Thesis (CNAA), City of London Polytechnic, 1980.

9. Roberts, E F I., Hunt, R. Optica Acta 1982, 29, 1683-1689.

10. Mizuno, T., Shindo, T., Morozumi, T. Corr.Eng.,1977, 26, 177-183.

11. Philips, I I., Poole, P, Shreir, L L. Corrosion, 1972, 12, 855-866.

12. Hamilton, M A. MSc Report (CNAA), City of London Polytechnic, 1980.

13. T Smith. J Opt.Soc.Am., 1972, 62, 774-780.

14. Matsuda, S., Sugimoto, K. J.Jap.Inst.Met., 1981, 45, 203-209.

15. Klein, M.V., "Optics", John Wiley (New York) 1970. 